DOI: $12737 / 25201$

УДК $630 * 3$

\author{
МЕТОДИКА ФОРМИРОВАНИЯ СИСТЕМЫ ЛЕСОЗАГОТОВИТЕЛЬНЫХ МАШИН \\ B. О. Мамматов ${ }^{1}$ \\ кандидат технических наук, доцент А. П. Мохирев ${ }^{1}$ \\ 1 - Лесосибирский филиал ФГБОУ ВО «Сибирский государственный аэрокосмический университет \\ имени академика М.Ф. Решетнева», г. Лесосибирск, Российская Федерация
}

\begin{abstract}
Многообразие природно-производственных условий, в которых приходится вести лесозаготовительную деятельность во многом затрудняет выбор лесозаготовительных машин для каждого отдельного предприятия отрасли имеющего в своем составе лесозаготовительные участки. В зависимости от многочисленных природных и производственных условий таких как: уклон местности, несущая способность грунтов, температура окружающей среды, максимальные капиталовложения и т.д., и широкой линейки лесозаготовительной техники представленной на рынке инженерно-техническим подразделениям предприятия решая задачу о покупке новой или замене угратившей свою работоспособность технике все труднее сделать правильный выбор. В рамках данной работы представлена методика по формированию системы лесозаготовительных машин с учетом природных и производственных условий в удобной форме, не требующая от специалиста особых знаний из области математического моделирования или других областей науки.. Согласно методике первым этапом является выбор базовой машины выполняющей первую и основную операцию по валке деревьев, далее необходимо выбрать вспомогательные машины, увязанные с базовой по параметрам производительности, чтобы сократить количество межоперационного запаса. Выбор базовой и вспомогательных машин производится при условии соответствия кандидатов исключающим и значимым показателям. Если в процессе выбора лесозаготовительная машина не соответствует критериям отбора по исключающим показателям далее она не принимает участие в отборе. Значимыми показателями можно пренебречь при несоответствии кандидатов заявленным требованиям. Работоспособность модели была проверена на примере лесозаготовительных участков предприятий Красноярского края весной 2016 года. В ходе проведения эксперимента была получена система лесозаготовительных машин отвечающая требуемым критериям отбора.
\end{abstract}

Ключевые слова: методика выбора системы лесозаготовительных машин, природно-производственные условия, базовая машина, вспомогательные машины.

\title{
THE TECHNIQUE OF FORMATION OF SYSTEM OF FORESTRY MACHINES
} V. O. Mammatov ${ }^{1}$

$\mathrm{PhD}$ in Engineering, Associate Professor A. P. Mokhirev ${ }^{1}$

1 - Lesosibirskiy Branch of the Reshetnev Siberian State Aerospace University, Lesosibirsk, Russian Federation

\begin{abstract}
A variety of natural-production conditions, which is necessary to conduct logging activities largely complicates the choice of forest machines for each individual company in the industry having logging sites in its composition. Depending on many natural and production conditions such as: slope, bearing capacity of soils, ambient temperature, maximum investments, etc., and the wide range of forestry equipment on the market, engineering divisions of the company solving a problem about the purchase of new or replacement of lost its performance machines are more and more difficult to make the right choice. This work presents a methodology for forming the system of forest machines with the natural and production conditions in a convenient form, not requiring special expert knowledge from the field of mathematical modeling or other areas of science. According to the methodology the first step is selection of basic machine and performing the first major operation in felling trees, then switch to the auxiliary machines which are linked to the underlying performance, to reduce the number of in-process stock. Selection of basic and auxiliary machines is provided that candidates and excludes important indicators. If in the process of selecting the logging machine does not meet the screening criteria for excluding indicators then it does not participate in the selection. Significant index can be neglected in case of discrepancy of candidates to stated requirements. The performance of the model was tested on the example of harvesting sites of the enterprises of the Krasnoyarsk region in spring 2016. In the course of the experiment the system of forest machines, meeting the required selection criteria, was obtained.
\end{abstract}

Keywords: the method of system selection of forest machines, natural-production conditions, basic machine, auxiliary machine. 
Лесной комплекс Российской Федерации, включающий в свой состав лесное хозяйство и лесопромышленные отрасли по заготовке и переработке древесины, занимает важное место в экономике страны.

Леса России - один из важнейших возобновляемых природных ресурсов составляют более четверти мировых запасов древесной биомассы и выполняют важнейшие средообразующие и средозащитные функции.

Заготовка древесины производится при помощи лесозаготовительных комплексов. Вне зависимости от классификации они имеют одну общую цель - заготовку древесных ресурсов. Правильно укомплектованный лесозаготовительный комплекс позволит с наибольшей производительностью и наименьшими затратами производить заготовку древесных ресурсов [2, 6, 10, 11].

Природно-производственные условия во многом являются основополагающими при выборе той или иной системы лесозаготовительных машин.

Цель данного исследования - создание методики по формированию системы лесозаготовительных машин с возможностью ее применения в различных природных и производственных условиях.

Подбором системы лесозаготовительных машин под различные природно-климатические и технико-экономические условия занимались многие исследователи [4, 7].

Предлагаемая методика построена на подбоpe базовой машины и вспомогательных машин.Общая схема разработанной методики представлена на рис. 1.

Исходными данными для решения задачи по формированию системы машин являются природные условия местности, на которой будет работать техника, производственные условия накладываемые эффективностью деятельности предприятия и технико- экономические показатели кандидатов на место в системе машин [8].

Под природными условиями подразумеваются такие ограничивающие выбор факторы, как: преобладающий уклон местности $i_{\text {местн }}[1]$; несущая способность грунта $\partial_{\text {грунт }}[5]$; средний диаметр в древостое $d_{\text {сред }}$ и температура окружающей среды $T_{\min }, T_{\max }$.

Производственные условия, такие как: плановая сменная производительность машины $Q_{\text {план.маш; пла- }}$ новая сменная производительность лесозаготовительного участка $Q_{\text {план.уч}}$, а так же максимальные капиталовложения $\mathrm{K}_{\max }$.

К технико-экономическим показателям рассматриваемых машин относятся; максимальный рабочий уклон $i_{\text {max }}$, удельное давление на грунт $\partial_{\text {маш }}[12]$, диаметр обрабатываемый рабочим органом $d_{\text {обр.раб.орг }}$, рабочий диапазон температуры окружающей среды $t_{\text {min, }} t_{\text {max }}$, сменная производительность $\Pi_{\text {см }}$, цена $\mathrm{C}$, количество базовых машин $n_{\text {баз }}$.

Когда имеются все исходные данные для последующих расчетов, производится выбор базовой машины (рис. 2).

Приоритетность выбора базовой машины обусловлена первоочередностью ее действий относительно других участников технологического процесса. Таким образом, вспомогательные машины подбираются под характеристики базовой машины.

Базовая машина, а точнее ее техникоэкономические показатели, являются основанием для всех последующих расчетов.

На рисунке ниже представлена схема выбора базовой машины.

Как видно из представленной схемы подбор базовой машины происходит в две стадии.

Во-первых,выбираются машины, которые удовлетворяют исключающим ограничениям. Под исключающими ограничениями понимаются такие ограниче-

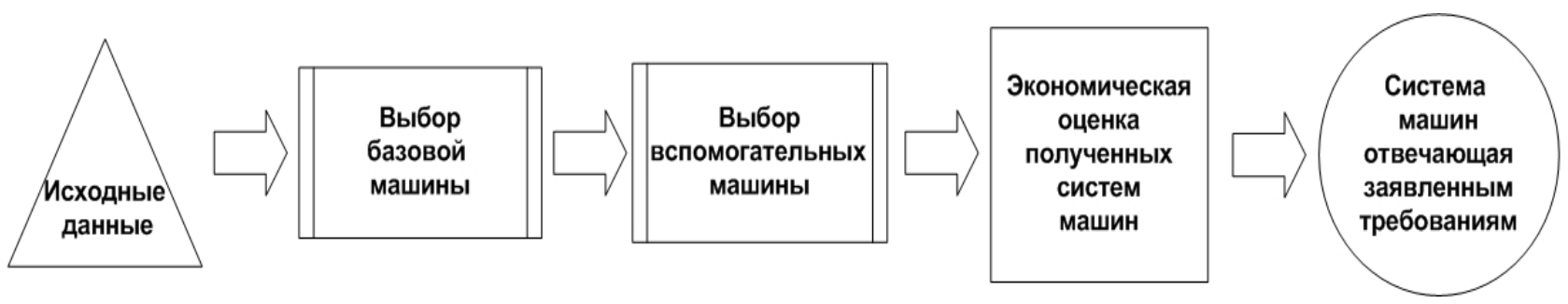

Рис. 1. Общая схема методики по выбору системы лесозаготовительных машин 


\begin{tabular}{|c|c|c|}
\hline Искпючающие огранчченчя & Значчмые показатели & Ограниченчя \\
\hline$i_{\max } \geq i_{\text {mecm }}$ & $\begin{array}{l}\text { УӘельные эксплуатационные } \\
\text { затрапы }\end{array}$ & $\begin{array}{l}\text { УЭЗ } \rightarrow \text { miп; } \\
\Pi_{\text {смбаз }} \geq \text { Qппан }\end{array}$ \\
\hline$\partial_{\text {маш }}<\partial_{\text {грунтा }}$ & 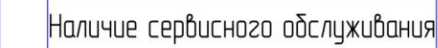 & Регчон \\
\hline$\left[\leq K_{\max }\right.$ & Гарантийный срок & Гаранпшப்ныப் срок $\geq 2000$ мот/час \\
\hline 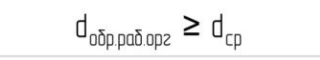 & ЭргономЈка & Coombemcmbue станðарmaм FOPS/ROPS/OPS \\
\hline$\Pi_{\text {см.боз }} \geq Q_{\text {ппон.маш }}$ & & \\
\hline$\dagger_{\max } \geq T_{\max }$ & & \\
\hline$t_{\min } \leq T_{\min }$ & \multicolumn{2}{|c|}{ Базољые машыны соопһетстъцюющие заданным параметрам } \\
\hline$\sum_{n \rightarrow \min }^{N} \Pi_{\tilde{\partial а з ~}} \Pi_{\text {см.доз }} \geq Q_{\text {ппан.पч }}$ & & \\
\hline
\end{tabular}

Рис. 2. Схема выбора базовой машины

ния, накладываемые природно-производственными условиями, при которых машина способна вести лесозаготовительную деятельность.

Во-вторых, производится отбор по значимым показателям. Значимые показатели - это техникоэксплуатационные показатели кандидатов на место в системе машин, которыми мы можем пренебречь при их несоответствии заявленным требованиям.

Если характеристики базовой машины соответствуют заданным ограничениям накладываемые природно-производственными условиями, то можно переходить к выбору вспомогательных машин.

На рис. 3 представлена схема выбора вспомогательных машин по исключающим и значимым показателям.

Как и в случае с базовой машиной, техникоэкономические характеристики вспомогательных машин должны удовлетворять исключающим и значимым ограничениям.
Если в ходе проведения работы получается несколько систем машин, в таком случае проводится их сравнительный анализ.

Анализ получившихся систем лесозаготовительных машин производится по критерию эффективности капиталовложений Э кап.влож $\rightarrow$ max.

При расчете эффективности капиталовложений используются следующие исходные данные.

Годовой объем заготовки - это тот объем заготовленной древесины, который устанавливается исходя из расчетной лесосеки лесозаготовительного участка.

Сменный объем устанавливается в зависимости от сменной производительности оборудования.

Число рабочих определяется исходя из сменного объема работ. Так если одна смена не справляется с поставленной задачей то к работе привлекается дополнительный штат сотрудников.

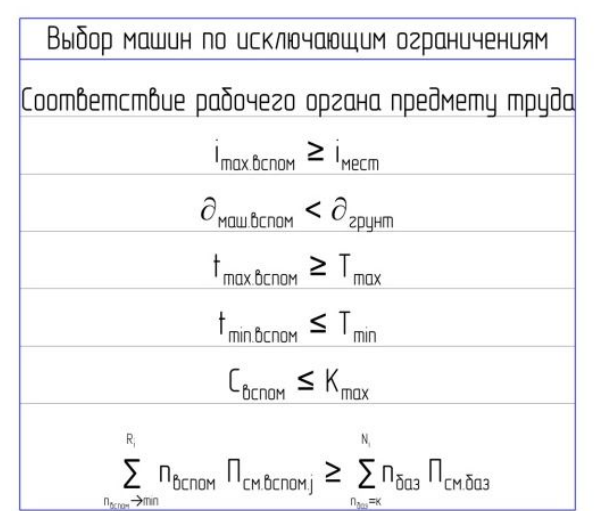

\begin{tabular}{|c|c|}
\hline \multicolumn{2}{|c|}{ Выбор машин по максимальному соответствию значчмым огранчченчям } \\
\hline Показапель & Органчченчя \\
\hline Общая база & 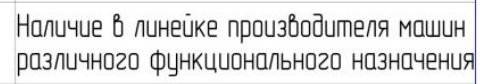 \\
\hline Крапностпь прочзВодительнности & $\Pi_{\text {сM.сеп }} \approx \Pi_{\text {смбоваз }}$ \\
\hline Удепьные эксппуапационные затрать & УЭЗ $\rightarrow$ miп; $\Pi_{\text {см.Вспом }} \geq$ Qплан \\
\hline Налччче серВисного обслуживания & Регчон \\
\hline Наðежность & Гарантиӵныப் срок $\geq 2000$ мот/час \\
\hline Эргономика & Coombemcmbue стандарmaм FOPS/ROPS/OPS \\
\hline
\end{tabular}

Рис. 3. Схема выбора вспомогательных машин 
В состав фонда заработной платы включаются начисленные предприятием суммы оплаты труда в денежной и натуральной формах заотработанное и неотработанное время, стимулирующие доплаты и надбавки, компенсационные выплаты, связанные с режимом работы и условиями труда, премии и единовременные поощрительные выплаты, а так же выплаты на питание, жилье, топливо, носящие регулярный характер. Если заготовка древесины происходит вахтовым методом то учитываем надбавку в размере 250 рублей ежедневно за работу данным методом согласно трудовому законодательству. Размер страховых взносов насчитывает $30 \%$ ежемесячно в зависимости от размера оплаты труда. Наиболее часто встречаемая форма оплаты труда сотрудников на лесозаготовительных участках - сдельная.

Затраты на горюче-смазочные материалы можно определить исходя из данных методических рекомендаций по бухгалтерскому учету горюче-смазочных материалов в сельскохозяйственных организациях (утв. Минсельхозом России 16.05.2005).

Сумма амортизационных отчислений включается в издержки производства (себестоимость) продукции и тем самым переходит в цену. Производитель обязан производить накопление амортизационных отчислений, откладывая их из выручки за проданную продукцию.

Затраты на приобретение запасных частей для системы машин можно рассчитать исходя из номенклатурных перечней заводов-производителей, номенклатурных тетрадях и у дистрибьюторов и включающих от 400 до 800 наименований деталей.

Себестоимость одного кубического метра заготовленной древесины определяется как отношение затрат на заготовку к фактическому объему заготовленного пиловочника.

При расчете капиталовложений учитываются: расходы на транспортировку и затраты на монтаж оборудования, стоимость инвентаря и инструментов, а так же утилизационный сбор. Транспортно-заготовительные расходы и затраты на демонтаж оборудования устанавливаются в размере $10 \%$ от стоимости оборудования. Стоимость инструмента, приспособлений и инвентаря принимается в размере $3 \%$ стоимости оборудования и строительных работ. Утилизационный сбор на покупку новой техники рассчитывается исходя из данных перечня видов и категорий машин и прицепов к ним (утвержденного постановлением Правительства РФ от 6 февраля 2016 года № 81) умножением базовой ставки в размере 150 тыс.рублей на соответствующий табличный коэффициент.

Прибыль от заготовки сортиментов определяем по формуле:

где С- себестоимость $1 \mathrm{~m}^{3}, \mathrm{p}$;

$$
\Pi_{\mathrm{p}}=Q_{\text {пр }}(Ц-\mathrm{C}),
$$

Ц - цена реализации $1 \mathrm{~m}^{3}, \mathrm{p}$.,

$Q_{\text {пр }}$ - годовой объем сортиментов, м $^{3}$,

При расчете прибыли необходимо так же учесть налог на прибыль в размере $20 \%$.

Коэффициент экономической эффективности определяется как отношение чистой прибыли к капиталовложениям.

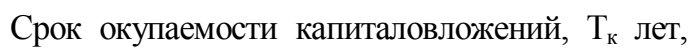
определяется по формуле:

$$
\mathrm{T}_{\mathrm{K}}=\frac{\mathrm{K}}{\Delta \Pi}
$$

где $\Delta$ - прирост прибыли, с учетом $20 \%$ налога, p.;

К - величина капитальных вложений, $\mathrm{p}$.

По результатам оценки экономической эффективности систем машин выбирается та, которая имеет наилучшие показатели.

Работоспособность данной методики была проверена на одном из лесозаготовительных участков Красноярского края.

В качестве примера был рассмотрен лесозаготовительный участок одного из крупнейших лесопромышленных предприятий находящийся на территории Туруханского лесничества Красноярского края [9]. Его основные характеристики представлены в табл. 1, 2 и на рис. 4.

Таблица 1

Характеристика лесофонда

\begin{tabular}{|c|c|}
\hline Средний запас $\mathrm{m}^{3} /$ га & 250 \\
\hline Средний диаметр, см & 25,3 \\
\hline Преобладающая порода & Сосна \\
\hline
\end{tabular}

В качестве кандидатов на место в системе машин были отобраны основные представители лесозаготовительной техники на территории Красноярского края. Это сортиментная технология [3] на базевалочносучкорезно-ряскряжевочноймашиныPONSSE Bear, и транспортной машины PONSSE Buffalo. 
Таблица 2

Климатические условия

\begin{tabular}{|c|c|c|}
\hline \multirow{2}{*}{$\begin{array}{c}\text { Средняя } \\
\text { температура, }{ }^{0} \mathrm{C}\end{array}$} & Январь & $-20,5$ \\
\cline { 2 - 3 } & Июнь & 19,5 \\
\hline \multicolumn{2}{|c|}{ Продолжительность снежного периода, сутки } & 183 \\
\hline $\begin{array}{c}\text { Высота снежного } \\
\text { покрова в зимний } \\
\text { период, см }\end{array}$ & Средняя & 39 \\
\cline { 2 - 3 } & Максимальная & 59 \\
\hline
\end{tabular}

Валочно-пакетирующие машины отечественного и зарубежного производства такие как; ЛП-19А, ЛП60-01A, JohnDeere 903 К, Caterpillar541S-2 и KomatsuXT460L-3.

Трелевочные тракторы производства отечественного и зарубежного машиностроения; ТT-4M, JohnDeere 748 H, Caterpillar525 С и NOENF160-4R.

Мобильные сучкорезно-раскряжевочные машины JohnDeere 2154 D, Caterpillar320 DFM и PC220-8

В качестве базовых машин были отобраны все валочно-пакетирующие машины представленные на рассмотрение.

Валочно-сучкорезно-ряскряжевочная машина PONSSE Bearне прошла по исключающему критерию производительности. Так как плановая производительность участка превосходила технические возможности данной лесозаготовительной машины.

При выборе вспомогательных машин оказалось, что только дваиз представленных производителей лесозаготовительной техники выпускают машины различного функционального назначения. Это компании JohnDeere и Caterpillar.

Таким образом, согласно методике, были получены две системы лесозаготовительных машин отвечающие заявленным требованиям. Их состав представлен в табл. 3.

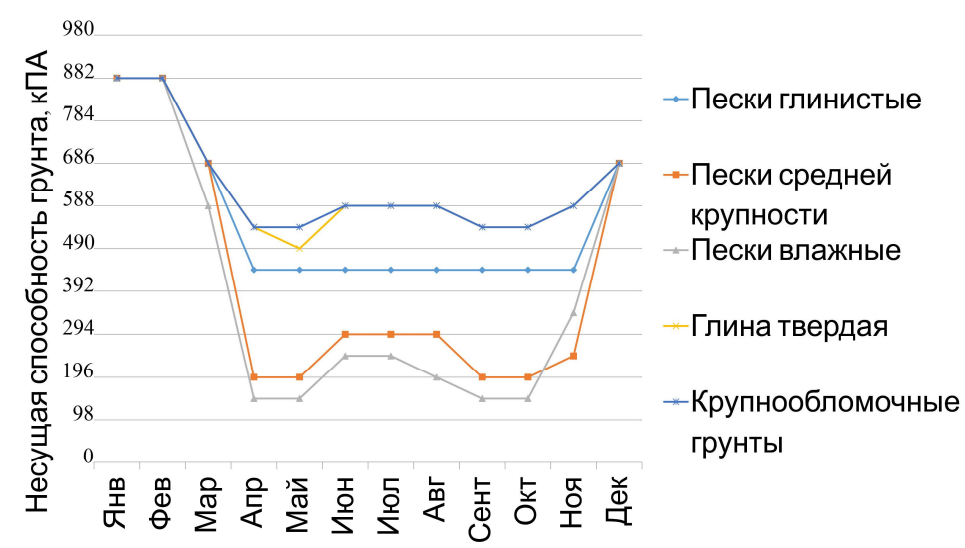

Рис. 4. Несущая способность грунта на рассматриваемом участке 


\section{Библиографический список}

1. Bont, L. G. Concurrent optimization of harvesting and road network layouts under steep terrain [Text] / L. G.Bont, H. R. Heinimann, L. C. Richard // Annals of Operations Research. - 2012. - No. 232. - Pp. 41-64.

2. Gerasimov, Y. Industrial round-wood damage and operational efficiency losses associated with the maintenance of a single-grip harvester head model: a case study in Russia [Text] / Y. Gerasimov, A. Seliverstov, V. Syunev // Forests. - 2012. - T. 3. - № 4. - C. 864-880.

3. Gerasimov, Y. Development trends and future prospects of cut-to-length machinery [Text] / Y. Gerasimov, A. Sokolov, V. Syunev // Advanced Materials Research. - 2013. - T. 705. - C. 468-473.

4. Shegelman, I. Optimization of a forest harvesting set based on the Queueing Theory: Case study from Karelia [Text] / I. Shegelman, P. Budnik, E. Morozov // Lesn. Cas. For. J. - 2015. - No. 61. - Pp. 211-220.

5. Виногоров, Г. К. Некоторые лесоэксплуатационные характеристики почвенно-грунтовых условий и рельефа [Текст] / Г. К. Виногоров // Вопросы технологии и механизации лесосечных работ : сб. науч. тр. ЦНИИМЭ. - Химки, 1982. - С. 5-7.

6. Куницкая, О. А. Актуальные проблемы лесозаготовительного производства в России на рубеже 2015 года [Текст] / О. А. Куницкая // Актуальные направления научных исследований XXI века: теория и практика. - 2014. - Т. 2. - № 5-4 (10-4). - С. 183-186.

7. Макуев, В. А. Формирование парка лесосечных машин для лесозаготовительного предприятия [Текст] : моногр. / В. А. Макуев. - М., 2004. - 184 с.

8. Мохирев, А. П. Критерии оценки технологий лесозаготовительных производств [Электронный ресурс] / А. П. Мохирев, П. Ф. Мохирев // Инженерный вестник Дона. - 2015. - Т. 38. - № 4 (38). - С. 122. Режим доступа: ivdon.ru/ru/magazine/archive/n4y2015/3318.

9. Мохирев, А. П. Исследование специфики лесозаготовок в Красноярском крае [Текст] / А. П.Мохирев, П. Ф. Мохирев // Resources and Technology. - 2015. - Т. 12. - № 2. - С. 98-108.

10. Шегельман, И. Р. Анализ эффективности сортиментной заготовки леса [Текст] / И. Р. Шегельман, В. И.Скрыпник, Р. А. Петухов // Ученые записки ПетрГУ. Серия «Естественные и технические науки». - 2008. № 3(94). - C. 94-103.

11. Шегельман, И. Р. Анализ показателей работы и оценка эффективности лесозаготовительных машин в различных природно-производственных условиях [Текст] / И. Р. Шегельман, В. И.Скрыпник, А. В. Кузнецов // Ученые записки ПетрГУ. - 2010. - № 4. - С. 66-75.

12. Шеховцев, Д. И. Оценка проходимости трелевочных тракторов [Текст] / Д. И. Шеховцев // Исследования лесопромышленных тракторов. Труды ЦНИИМЭ. - Химки, 1982. - С. 14-15.

\section{References}

1. Bont L. G., Heinimann H. R., Richard L. C. Concurrent optimization of harvesting and road network layouts under steep terrain. Annals of Operations Research, 232, 2012, pp. 41-64.

2. Gerasimov Y., Seliverstov A., Syunev V. Industrial round-wood damage and operational efficiency losses associated with the maintenance of a single-grip harvester head model: a case study in Russia - Forests. 2012, Vol. 3, no. 4. pp. 864-880. doi: 10.3390/f3040864

3. Gerasimov Y., Sokolov A., Syunev V. Development trends and future prospects of cut-to-length machinery Advanced Materials Research. 2013, Vol. 705, pp.468-473. doi: 10.4028/www.scientific.net/AMR.705.468

4. Shegelman I., Budnik P., Morozov E.:Optimization of a forest harvesting set based on the Queueing Theory: Case study from Karelia. Lesn.Cas. For.J., 2015, 61,pp. 211-220.

5. Vinogorov G. K. Nekotorye lesoekspluatatsionnye kharakteristiki pochvenno-gruntovykh usloviy I rel'efa [Some lesoeksportnye characteristics of the soil conditions and terrain].Voprosy tekhnologii I mekhanizatsii lesosechnykh rabot :sbornik nauchnykh trudov TSNIIME [The technology and mechanization of logging operations : collection of scientific works TSNIIME]. Khimki, 1982, pp. 5-7 (In Russian). 
6. Kunickaja O.A. Aktual'nye problem lesozagotovitel'nogo proizvodstva v Rossiinarubezhe 2015 goda [Actual problems of timber production in Russia at the turn of 2015] - Aktual'nye napravlenija nauchnyh issledovanij XXI veka :teorijaipraktika [Current research trends of the XXI century: Theory and Practice] 2014, Vol. 2, no. 5-4 (10-4), pp. 183-186.(In Russian).doi: 10.12737/7092

7. Makuev, V.A. Formirovanie parka lesosechnykhmashindlyalesozagotovitel'nogopredpriyatiya [The formation of the Park, logging machinery for logging companies].Moscow, 2004, 184 p (In Russian).

8. Mokhirev A.P., Mokhirev P.F. Kriterii otsenki tekhnologiy lesozagotovitel'nykh proizvodstv [Evaluation criteria of technologies for logging industries] Inženernyjvestnik Dona[Engineering journal of don]. 2015, Vol. 38, no.4 (38), pp. 122.Available at: ivdon.ru/ru/magazine/archive/n4y2015/3318.(In Russian).

9. Mokhirev A.P., Mokhirev P.F. Issledovanie spetsifiki lesozagotovok v Krasnoyarskom krae [Study of the specifics of logging in Krasnoyarsk region] Resources and Technology. 2015, Vol. 12, no.2, pp.98-108.(In Russian).doi: 10.15393/j2.art.2015.3061

10. Shegel'man I. R.,Skrypnik V. I., Petukhov R. A. Analiz effektivnosti sortimentnoy zagotovki lesa [Analysis of the effectiveness of CTL logging].UchenyezapiskiPetrGU.Seriya «Estestvennye I tekhnicheskie nauki»[PetrGU's scientific notes.A series of "Natural and technical Sciences"]. 2008, no. 3(94), pp. 94-103(In Russian).

11. Shegel'manI.R., Skrypnik V.I., Kuznetsov A.V. Analiz pokazateley raboty I otsenka effektivnosti lesozagotovitel'nykhmashin $v$ razlichnykhprirodno-proizvodstvennykhusloviyakh [The performance analysis and evaluation of the effectiveness of forest machines in different natural production conditions]Uchenyezapiski PetrGU[PetrGU's scientific notes].2010, no.4,pp. 66-75(In Russian).

12. Shekhovtsev D. I. Otsenka prokhodimosti trelevochny khtraktorov [Assessment of the patency of the skidder] Issledovaniyalesopromyshlennykhtraktorov. Trudy TsNIIME[The research problem underlying forestry tractors. WorksTSNIIME]. Khimki, 1982, pp. 14-15 (InRussian).

\section{Сведения об авторах}

Мамматов Владимир Олимбаевич - студент-магистрант кафедры технологии лесозаготовительных и деревоперерабатывающих производств Лесосибирского филиала ФГБОУ ВО «Сибирский государственный аэрокосмический университет имени академика М.Ф. Решетнева», г. Лесосибирск, Российская Федерация; e-mail:mammatov1@mail.ru.

Мохирев Александр Петрович - доцент кафедры технологии лесозаготовительных и деревоперерабатывающих производств Лесосибирского филиала ФГБОУ ВО «Сибирский государственный аэрокосмический университет имени академика М.Ф. Решетнева», кандидат технических наук, доцент, г. Лесосибирск, Российская Федерация; e-mail:ale-mokhirev@yandex.ru.

\section{Information about authors}

Mammatov Vladimir Olimbaevich - student-graduate student of Department of technology of logging and wood processing industries Lesosibirsk branch «Reshetnev Siberian State Aerospace University», Lesosibirsk, Russian Federation; e-mail: mammatov1@mail.ru.

Mokhirev Aleksandr Petrovich - Associate Professor of Technology of logging and wood processing industries Lesosibirskiy Branch of the Reshetnev Siberian State Aerospace University, PhD in Engineering, Associate Professor, Lesosibirsk, Russian Federation; e-mail: ale-mokhirev@yandex.ru. 